\title{
Travel as pedagogy: embodied learning in short-term study abroad
}

\section{Bridget McKenney Costello}

Department of Criminal Justice \& Sociology, King's College, Wilkes Barre, PA, USA.

\begin{abstract}
In this paper I discuss a model for creating embodied learning opportunities in study abroad curricula, which purposefully uses students' physical movement through foreign landscapes to inform and enhance their understanding of local social, political, economic, cultural, and historical phenomena. Pedagogical tactics include: challenging and reframing the common distinction between "important" and "unimportant" instructional times and places; loosely structured itineraries that allow for greater student autonomy and collaboration; seeking multiple vantage points (both geographic and textual) from which to observe and analyze locations ; purposeful and attentive travel between study locations that helps connect cognitive to visceral experience. These tactics help students cultivate the ability to read landscapes, a skill that them to understand a landscape not only as historical narrative but also as a social actor that influences and is influenced by the everyday practices of people who inhabit it. To demonstrate these strategies, I discuss how they were implemented in a recent short-term study abroad program to various sites within the former Yugoslavia.
\end{abstract}

Keywords: study abroad; embodied learning; spatial learning; experiential learning; intercultural competence; Balkan studies; higher education 


\section{Introduction}

Social scientists commonly recognize the landscape as a palimpsest wherein structures built in the past, and the ideas that informed and are inscribed in their physical structure, continue to be visible in the present day. Because the built environment requires humans to maintain it, the various dynamics of social action are inscribed upon and can be read from numerous aspects of landscapes (spatial relationships between buildings and other elements; patterns of use, maintenance, and neglect). Once built, landscape elements operate as a further constraint upon human action, both practically and symbolically, and serve as a resource for the construction of collective - and often hotly contested - ethnic, religious, and political identities. As such, landscape elements frequently serve as visible, material focal points for struggles over both resources and meanings. While different forms of media (books, photos, audio recordings, film, etc.) may be used to describe the various relevant aspects of landscapes that contribute to the narrative of place, all fall short in important respects. To fully understand landscapes - their relationship with people and other places, their evolution over time, the multiple and contested meanings inscribed upon them by contemporary and historical constituencies - they must be experienced from multiple angles, over a period of time, with all of their attendant sounds, smells, and sensations, and subject to all of the thoughts and emotions that they may evoke. They must be read, in person, as texts. As with any other type of text, a careful and thorough reading of landscapes reveal multifaceted narratives about the humans who inhabit them.

Here, I describe some considerations in constructing and teaching a college-level study abroad curriculum where the reading schedule consists of landscapes, landmarks, and the spaces that connect them, using a recent short-term program to Yugoslavia to illustrate important strategies involved with this approach. An embodied learning approach moves beyond using travel as a simple practical necessity for visiting multiple sites, and towards using the act of travel itself as a pedagogical tool that imparts a visceral, embodied knowledge of landscapes and the layers of meaning with which they are inscribed.

\section{Short term study abroad and embodied learning - challenges and opportunities}

Pedagogies of embodied cognition, or embodied learning, are premised upon findings in neuroscience and cognitive psychology indicating that sensory perceptions and processing structures are closely aligned, and in some instances overlap, with processes and structures associated with memory and comprehension (Nguyen and Larson 2015; Skulmowski and Rey 2018). In simple form, we are better able to recall an event with which we associate a specific sensory experience, laying the foundation for better comprehension. Embodied learning approaches range from minimal (creating unique gestures to aid memorization of 
vocabulary terms) to immersive (using improvisational skits to develop understanding of micro-sociological theory).

All short-term study abroad programs - meaning, programs in which students travel in a group with teaching faculty, lasting anywhere from one to four weeks - are inherently embodied experiences to some degree though the involvement of physical travel. However, the mere fact of physical movement through space does not in and of itself guarantee embodied learning, which occurs when sensory experiences are directly and coherently linked to learning objectives; ensuring embodied learning requires greater intentionality in planning and executing the spatial and experiential aspects of the curriculum, as well as attention to elements of the framing and execution of programs that may undermine embodied learning objectives.

\subsection{The tyranny of "important" times and places}

One of the principle challenges to creating deep learning in short-term study abroad programs is the way in which administrative and logistical operations frame and constrain the learning environment. Short-term study abroad programs are a powerful and effective means to increase the availability of foreign travel experience to students who may be otherwise precluded due to time and/or resource constraints (Mills, Vrba, and Deviny 2012). However, marketing materials for these programs often conflate their touristic popularity with their academic importance as a mechanism for attracting student participants, and program itineraries show a strong magnetic pull towards the "important" sites that appear on postcards and figure largely in promotional brochures. Recruiting students based on the touristic appeal of "important" places thus initially frames the program as a touristic experience; no matter how carefully conceived and thoughtfully instructed these courses may be, students who understand certain sites as "important" come to view the temporal and geographic spaces between these "important" sites as vacancies to be filled with down-time activities (texting, chatting, napping, shopping) that are unrelated to course content. This framing is further reinforced by well-meaning program leaders who desire to give students a value-packed experience, and thus afford students scant free time to rest from the myriad physical, mental, and social demands of intensive study travel.

A second and related challenge is the temptation for students to adopt the "tourist gaze" (Urry 1990) during both "important" and "unimportant" time, wherein all aspects of the students' surroundings in unfamiliar places are treated as exotic and representative of a uniquely local perspective and culture. The problem here lies not with the heightened scrutiny that characterizes the tourist gaze - which, if properly directed, can be profoundly beneficial - but instead in its unexamined character. Students may be disinclined to share their personal reflections with faculty, particularly when these observations occur in "unimportant" times and places, due to concerns that their personal experience is irrelevant 
to the course (indeed, this notion is sometimes cultivated by program leaders and study abroad staff, who refer to the program leaders' "dual role" as both instructors and chaperones, and who may advise students to remain mindful of the distinction). When the tourist gaze occurs during "unimportant" time, it remains uncritical, unscrutinized, and beyond the reach of faculty who are equipped to provide additional expertise that helps students contextualize, interpret, and curate their observations. Redirecting this tourist gaze from its essentialist and ethnocentric foundation involves harnessing the students' curiosity, regardless of its original direction, and providing a mechanism and a rationale for drawing students' individual sensory experiences into the realm of collective scholarly inquiry.

\subsection{Reframing the value and purpose of time and place}

Challenging the bifurcated framing of "important/ instructional" and "unimportant/ free/ leisure" times and locations, and the corollary danger of the unchallenged touristic gaze, requires incorporating both practical and symbolic alternatives. If students are expected to remain alert and attentive during times when the group is convened, then as a practical matter they must be allowed sufficient individual time to rest their bodies and minds alike from the heavy demands of instructional travel. As a symbolic matter, the language of "important/instructional" time and place and "unimportant/free/leisure)" time and place must be replaced with the language of "group" time and "individual" time, which vary not by importance or instructional value, but instead by the orientation of each student's attention to collective aims (activities oriented towards group-level analysis of the landscape) versus personal aims (activities that satisfy individual curiosity, needs for rest and relaxation, etc.), neither of which takes precedence in instructional importance and both of which actively contribute to the students' ability to read landscapes. Along with this reframing language, "individual time" must be carefully protected from the temptation to scale it back when the activities occurring in "group time" overrun their time. Students should be allowed some control over group time, including directing the group's attention to sites that aren't on the itinerary and introducing topics and observations of personal interest and inquiry. To allow for student autonomy and serendipitous discovery of landscape elements, itineraries must be flexible enough to be easily changed if the situation demands (for this reason, walking and public transportation are preferred for local travel). For both group and individual time, students should be reminded that their most important discoveries and contributions to the group may occur in what would normally be considered the "unimportant" places and times.

\section{Travel as pedagogy}

To illustrate the advantages of an embodied learning environment in short-term study abroad, I draw upon my experience co-directing a college-level program across some of the 
states of the former Yugoslavia. This 3-credit course, titled "Twice There Was A Country," was taught collaboratively by an historian (my colleague) and a sociologist (me) to develop students' understanding of borders - how they are constructed and naturalized, the ideological work that they perform, and their consequences for human populations - as they occur during the formation and breakup of the Yugoslavian state in the $20^{\text {th }}$ century. Throughout the nineteen day program, during which we traveled through sites in Serbia, Macedonia, Bosnia \& Herzegovina, and Croatia, undergraduate students encounter visual evidence of both Yugoslav and post-Yugoslav nationalisms, the human and environmental casualties of the Balkan Wars, the ruin / re-appropriation / resurrection of Communist-era sites and monuments, and the revered and abandoned touchstones of collective historical identity; meanwhile, students read texts written from a variety of disciplinary perspectives as well as from popular media, and keep a journal that records their experiences, perceptions, and ideas as they see fit.

One program day illustrates our encounters with many of these sights, the itinerary which reads in its entirety as follows: "June 4 - Mostar: Old Bridge, Bruce Lee statue, Partisan Monument." During our second day in Mostar, Bosnia \& Herzegovina, we began the day by walking from our lodgings to a copy shop, where we ordered each student copies of two articles that my colleague and I located in response to a question posed by a student the previous day. We then walked to the partisan monument on the outskirts of town, a Communist-era park that has since been overtaken by weeds and signs of vandalism, and spent some time exploring and remarking upon its similarity to a photograph of the park from the 1980s that students had seen previously, the placement and content of vandalistic acts, the mood evoked by the architectural elements, and the remarkable volume of insect chatter that was the dominant sound of the place. Our walk back towards the center of town took us through the university section and along shady streets lined with cafes, where we stopped for a few minutes to take in refreshments and discuss students' impressions of the park. After picking up our photocopies, we strolled through a large neighborhood park containing a statue of Bruce Lee; this statue was erected in the early 2000s when the ravages of the Balkan Wars were still fresh in local memory, and during a time when the only statue design that could win the approval of the majority of Mostar residents was of a pop culture figure with no connection whatsoever to the region. Students posed for pictures with the Bruce Lee statue, and then we continued to walk back towards the center of town. We happened upon a small cemetery in a residential neighborhood, occupying a small single-dwelling lot, wherein every grave marker was inscribed with dates of death in the early 1990s - dates corresponding to the siege of Mostar in 1993-94, during which the Ottoman-era Stari Most (Old Bridge) was destroyed by Croatian forces. Our walking route led us across the emerald green Nerevta River, which continues to serve as the de facto border between the Croat/Catholic west side and the Bosniak/Muslim east side of Mostar; we walked past countless buildings that remain in use but still bear visible shell marks from 
that period, and towards the heart of the old town surrounding the rebuilt Stari Most, crowded with souvenir shops, restaurants, and tourists. Before reaching the bridge, we ascended the minaret at the Koski Mehmed Pasha Mosque, which offers a panoramic view of Mostar and requires a stomach-churning climb (and descent) of a narrow, steep, winding, and congested $16^{\text {th }}$ century stone staircase. From that vantage point we could easily observe across the river, atop Hum Mountain on the Croat side of town, the enormous Millennium Cross constructed in 2002. We then continued our walk over the reconstructed Stari Most, the stones of which are so smoothly polished by fifteen years of heavy tourist foot traffic that the surface is slippery even under the driest conditions and downright treacherous when wet. A short walk through another residential neighborhood lead back to our hotel, where we allowed everyone a few minutes to refresh themselves before a group lunch. Throughout the morning, we engaged in ongoing discussion with students, either as an entire group (consisting of two faculty and seven students) whenever the group was stationary as well as in smaller ever-shifting groups while walking.

This small portion of our travels, which represents the typical manner in which we conducted group activities throughout our travels, illustrates some of the key tactics we employed to enhance the students' understanding of the landscape's narrative - in this

instance, characterized by spatialized ethnic conflict and competing efforts to both commemorate and obscure a difficult recent past - by linking it with their visceral, sensory, embodied experiences within that landscape.

\subsection{Crossing borders}

This practice (for which our study abroad model is named) aims to give students an embodied sense of borders (political, cultural, ethnic, economic) and their consequences. Many borders - such as the unofficial border marking the high degree of residential segregation between Croat Catholics and Bosniak Muslims - tend to escape the notice of study abroad students but capture their curiosity once they are made known. Physically walking across the border within the span of two minutes creates a visceral understanding of the fact that all borders are socially constructed, and that what may seem to be 'natural' to people within a society (the spatial and social division between Croats and Bosniaks) may be imperceptible to outsiders even when it is marked by an obvious physical feature (such as the Neretva River).

\subsection{Travel time as instructional time}

No activity that contributes to the group's collective goal of reading the landscape is considered unimportant. Stops at itinerary sites (the Old Bridge, the partisan monument) are on equal footing as visits to unplanned sites (the cemetery, the minaret, the café, the shellpocked buildings, the copy shop). All contribute to the overall sensory experience of the 
landscape - the sound of chirping insects or thousands of tourists' feet, the smell of a pastry shop or dog feces, religious symbols that precipitate a fluttering of joy or sorrow - that students are instructed and encouraged to use in their reading, writing, and thinking about the landscape's narrative, not only as mnemonic aids but also as landmarks in their own right.

\subsection{Flexible itineraries that allow for serendipitous learning}

Incorporating mundane, visceral, and otherwise "unimportant" experiences into the practice of reading the landscape can only be accommodated when itineraries remain flexible, and students are encouraged to take the initiative in suggesting sites, requesting breaks, and offering questions and interpretations that inspire detours. In this context, faculty are likewise understood as free to opportunistically modify the itinerary, in ways both small (a ten minute stop at a cemetery that illustrates the human toll of the siege of Mostar) and large (an unplanned but highly impactful four hour visit to Tito's bunker the previous day, which had only very recently opened to visitors).

\subsection{Bridging scholarly/narrative texts and the visceral/emotional 'text' of landscapes}

During our travel, students were assigned readings that provide scholarly perspectives from multiple disciplines, as well as personal accounts that describe the emotional and sensory experiences of places that we visited. For instance, in preparation for our visit to Mostar, students read an autoethnographic piece by historian Fedja Buric (2016) that offers both description and scholarly perspective on his experience as a 'mixed marriage' (Croat and Bosniak) child during the breakup of Yugoslavia. This piece, and others that we assigned, are put forth as models of reflexivity, where authors use personal perspectives / experiences / sensations to describe and inform rigorous scholarly analysis. In both group conversation and their individual journals, students are prompted to pay attention to their own embodied experience as a means to gain insight into the experiences of others, and the reflections of this experience within the landscape itself.

\section{Conclusion}

Student response to this approach is overwhelmingly positive. In student evaluations administered by study abroad staff, our students reported an appreciation for the degree of reciprocity between faculty and students, the opportunity shared by students and faculty to alter itineraries when serendipitous opportunities presented themselves, and the increase in their understanding of the region. Further, performance on student work was remarkably and consistently high as measured by both course-specific rubrics and by the Intercultural Knowledge and Competence rubric (AAC\&U 2009), despite significant variability in 
student skills prior to travel as demonstrated by students' transcripts and pre-departure assignments.

The main challenges in implementing the Crossing Borders model relate to the social norms and personal dispositions which are commonly attached to the roles of faculty and student. As with any "pedagogy of experience" (Viera 2010), in order to be successful, the travel group must develop strong norms of transparency, cooperation, and openness to serendipity. Faculty must relinquish some degree of control over the details of both travel itinerary and course structure, while students must not be tempted to confuse this invitation to collaboration with an invitation to mutiny and/or anarchy.

This model - which includes applying embodied learning tactics to short-term study abroad and teaching from a 'reading landscapes' perspective - is widely applicable to programs across the social sciences and humanities, and lends itself to an interdisciplinary and collaborative approach. Many of these tactics may also be adopted for domestic travel experiences, although in this case increased attention must be paid to strategies for stripping away the students' sense of relative familiarity with domestic landscapes to ensure that they remain attuned to its most instructive - naturalized, marginalized, taken-for-granted, "unimportant" - aspects.

\section{References}

Association of American Colleges and Universities (AAC\&U). (2009). Intercultural knowledge and competence VALUE rubric.

Buric, F. (2016). Confessions of a 'Mixed Marriage Child'. Diary in the Study of Yugoslavia’s Breakup. Südosteuropa, 64(3), 325-343.

Mills, L. H., Vrba, T., \& Deviney, D. (2012). Enriching the short-term study abroad program: A case study. ASBBS Proceedings, 19(1), 950.

Nguyen, D. J., \& Larson, J. B. (2015). Don't forget about the body: Exploring the curricular possibilities of embodied pedagogy. Innovative Higher Education, 40(4), 331-344.

Skulmowski, A., \& Rey, G. D. (2018). Embodied learning: introducing a taxonomy based on bodily engagement and task integration. Cognitive research: principles and implications, 3(1), 6 .

Urry, J. (1990). The tourist gaze: leisure and travel in contemporary societies. London; Newbury Park: Sage Publications.

Vieira, F. (2010). Towards teacher and learner autonomy: exploring a pedagogy of experience in teacher education. Revista Canaria de Estudios Ingleses, 61, 13-27. 